\title{
LOS MEDIOS DEFENSA DE LOS OPERADORES ECONÓMICOS ANTE LA LIBERTAD DE ESTABLECIMIENTO Y CIRCULACION EN EL MARCO DE LA LEY DE GARANTÍA DE LA UNIDAD DE MERCADO
}

\author{
Martín Bassols Coma \\ Catedrático de Derecho Administrativo. Abogado llustre Colegio Madrid
}

Artículo Recibido: 23/07/2015

Artículo Aceptado: 25/02/2015

\section{Introducción}

La Ley 20/2013 de 9 de diciembre de Garantía de la Unidad de Mercado por su densidad e innovaciones está destinada a tener un importante impacto en nuestro ordenamiento jurídico, tanto en el orden subjetivo ( acceso a actividades económicas en condiciones de mercado y su ejercicio por parte de operadores legalmente establecidos en cualquier lugar del territorio nacional, según en el artículo 2) como en la dimensión propiamente territorial de la Unidad de Mercado a efectos que< ninguna autoridad pueda obstaculizar directa o indirectamente> la libre circulación y establecimiento de bienes y servicios (art1.2 ). Si bien esta última dimensión territorial requerirá por su complejidad un dilatado periodo de acoplamiento institucional y administrativo para implantar la eficacia en todo el territorio nacional de las actuaciones administrativas según el lugar de origen y el de destino (art 19 y 20), lo cierto es que los medios de defensa que se otorgan a los operadores económicos ( expresión esta última que según el anexo equivale a <cualquier persona física o jurídica o entidad que realice una actividad económica en Espasa) son plenamente operativos desde la entrada en vigor de dicha ley, por lo que resulta de interés conocer panorámicamente sus mecanismos aplicativos ya que cabe presumir que la aplicación de la ley generara una gran religiosidad.

II Medios de defensa en garantía de la unidad de mercado. Legitimación de operadores económicos y organizaciones representativas de los operadores económicos: cámaras oficiales de comercio y asociaciones profesionales

Como norma general se establece que los operadores económicos podrán siempre interponer los recursos administrativos y o jurisdiccionales que procedan contra las disposiciones o actos que limitan o desconocen la libertad de establecimiento y de circulación. Ahora bien con carácter alternativo la Ley de Garantía de la Unidad de Mercado les ofrece unos medios de defensa singulares y especialmente potentes: una

WPS RI-SHUR, n2, 2015, vol.1, ISSN: 2387-1768 


\section{WPSReview International on Sustainable \\ Housing and Urban Renewal (RI-SHUR)}

Reclamación especial en vía administrativa ante la Secretaria del Consejo de la Unidad de Mercado (en adelante SCUM) (arte 26) y un recurso contenciosoadministrativo especial a cargo de la Comisión nacional de los Mercados y la Competencia (en adelante CNMYC) (art 27 de la LEY y arts. 127 (bis a querer) de la Ley de la Jurisdicción Contenioso- administrativa, en adelante, LJCA) que podrá interponerlos de oficio o a petición de un operador económico. La utilización de estos procedimientos alternativos tiene dossingularidades. Una de carácter limitativo, en la medida que en las reclamaciones ante SCUM cuando existan motivos de impugnación distintos de la vulneración de la libertad de establecimiento o de circulación deberán hacerlos valer de forma separada a través de los recursos administrativos y jurisdiccionales ordinarios $Y$ otra de carácter favorable, en la medida que el operador que hubiese recurrido separadamente en víacontenciosoadministrativa podrá acumular su recurso contencioso-administrativo al promovido por CNMYC siempre que se dirija frente a la misma disposición o actuación y se funde análogamente en la vulneración de la libertad de establecimiento o de circulación (art 127 ter.9 LJCA).

Para la utilización de estos medios de defensa que a continuación analizarnos, la ley 20/2013 otorga en primer lugar ,lógicamente, a los operadores económicos que entienda se ha vulnerado sus derechos o intereses legítimos por < alguna disposición de carácter general, acto, actuación, inactividad o vía de hecho que puede ser incompatible con la libertad de establecimiento o de circulación $>Y$ asimismo podrán utilizar las referidas vías las Cámaras Oficiales de Comercio y Asociaciones profesionales < en defensa de los intereses colectivos que representa>. Inexplicablemente, la reciente ley 4/2014 de 1 de abril (BOE 2 de abril) que ha reformado las Cámaras, pasándose a denominarse ahora Cámaras de Comercio. Industria, Servicios y Navegación no ha previsto ni desarrollado esta importante novedad que le ha propiciado la Ley de Garantía de la Unidad de Mercado.

\section{Reclamación administrativa ante la secretaria del Consejo para la Unidad de mercado}

Los operadores económicos y demás entidades legitimadas podrán dirigirse a la SCUM- según la Orden ECC /250/2014 de 20 de febrero dicho organismo será desempeñado por la Subdirección General de Competencia y regulación económica del Ministerio de Economía y Competitividad- frente a toda actuación que agotando o no la vía administrativa sea susceptible de recurso administrativo ordinario (reposición o alzada) y frente también a disposiciones de carácter general que puedan ser objeto de recurso contencioso administrativo.

WPS RI-SHUR, n2, 2015, vol.1, ISSN: 2387-1768 


\section{WPSReview International on Sustainable \\ Housing and Urban Renewal (RI-SHUR)}

Para la resolución de la Reclamación, la SCUM examinara el escrito de reclamación para comprobar que se trata de una actuación que pueda ser incompatible con la libertad de establecimiento o circulación, pudiendo inadmitirla cuando no concurrieren tales requisitos. A continuación, una vez admitida a trámite la remitirá al punto de contacto de la autoridad competente afectada (los llamados puntos de contacto para la Unidad de Contacto: CNMYC, SCUM Departamento Ministerial, autoridad designada por cada Comunidad Autónoma), para que en el plazo de cinco días formulen las aportaciones que consideren oportunas.

Recibidas estas aportaciones, la SCUM deberá realizar un informe de valoración sobre la reclamación en el plazo de diez que deberá ser tenido en cuenta por la autoridad competente a la hora de la resolución. Transcurridos quince días desde la presentación de la reclamación, el punto de Contacto correspondiente a la autoridad competente afectada, informara de la resolución adoptada por la autoridad competente. Indicando las medidas que se hayan adoptado para dar solución a la reclamación; trascurrido dicho plazo se entenderá desestimada por silencio administrativo negativo y que, por tanto, dicha autoridad mantiene su criterio respecto a la actuación objeto dela reclamación. Si los operadores económicos u organizaciones representativas, incluidas las Cámaras oficiales de Comercio y las Asociaciones profesionales (habrá que interpreta cuando hayan presentado efectivamente una reclamación) a la vista de la decisión de la autoridad competente no considerasen satisfechos sus derechos o intereses legítimos podrá dirigir su solicitud a la CNMYC para que interponga el recurso contencioso-administrativo especial a que se refiere el art 27 de la Ley.

\section{Recurso contencioso - administrativo para la garantía de la unidad de mercado: legitimación exclusiva de la interposición a la comisión nacional de los mercados y la competencia - efectos suspensivos automáticos desde la admisión a trámite del recurso}

Como hemos señalado anteriormente, solo la CNMYC está legitimada para la interposición de este recurso contencioso-administrativo especial, bien de oficio o a solitud de un operador económico. Cuando considere que una disposición, Acto, actuación, inactividad o vía de hecho procedente de cualquier Administración Pública sea contraria a la libertad de establecimiento o de circulación. La CNMYC podrá solicitar en el escrito de interposición la suspensión de la disposición, acto o resolución impugnada o cualquier otra medida cautelar. 


\title{
WPSReview International on Sustainable
}

\author{
Housing and Urban Renewal (RI-SHUR)
}

Solicitada la suspensión, esta se producirá automáticamente una vez admitido a trámite el recurso sin necesidad de afianzamiento; solo trascurridos tres meses de la suspensión, la Administración recurrida podrá solicitar el levantamiento de la misma. Se dará traslado de esta petición a la CNMYC para alegaciones y el Tribunal resolverá lo procedente en el plazo de diez días mediante Auto J.

El procedimiento del recurso contencioso-.administrativo para la Garantía de la Unidad de Mercado presenta las siguientes importantes novedades y está informado por la idea de urgencia y celeridad. El Órgano jurisdiccional competente para su resolución es la Audiencia Nacional (Sala de lo Contencioso- Administrativo) El plazo de presentación del recurso es de dos meses (cuando sea a solicitud de operador económico este plazo de dos meses se computara desde la solicitud ante el CNMYC). El Secretario judicial requerirá al órgano correspondiente la remiso del expediente en el plazo de cinco días, acompañado de datos en formes que se soliciten en el recurso; ahora bien la falta d envío del expediente no suspenderá el curso de los autos. Requiriéndose al demandante para que en el plazo de días improrrogables formalice la demanda y acompañe documentos oportunos (si el expediente se recibiera posteriormente se concederá un plazo adicional para alegaciones de las partes). Formalizada la demanda se dará traslado a las partes demandadas para que presenten contestación en plazo improrrogable de diez días y acompañen los documentos oportunos. El periodo de práctica de prueba no será en ningún caso superior a veinte días. Como especialidad digna de mención durante el procedimiento mediante Auto podrá acordarse, previa solicitud y audiencia de las partes, la intervención como parte recurrente de cualquier operador económico que tuviera interés directo en la anulación del acto, actuación o disposición impugnada y no la hubiere recurrido de forma independiente

Concluidas las actuación es, el Órgano jurisdiccional dictara la sentencia en el plazo d cinco días. La sentencia estimara el recurso < cuando la disposición, la actuación o el acto incurrieren en cualquier infracción del ordenamiento jurídico que afecte a la libertad de establecimiento o de circulación, incluida la desviación de poder $>$ e implicara la corrección de la conducta infractora, así como resarcimiento de daños y perjuicios, incluso el lucro cesante que dicha conducta haya causado.

\section{Dos especialidades procesales dignas de atención: la sentencia de <viva voz> y extensión de los efectos de las sentencias firmes a terceros}

En congruencia con la pretensión de abreviar el procedimiento judicial, el nuevo art 127. 6. ter. LJCA prevé que cuando se trate de asuntos en los que no quepa ulterior WPS RI-SHUR, n2, 2015, vol.1, ISSN: 2387-1768 


\title{
WPSReview International on Sustainable
}

\author{
Housing and Urban Renewal (RI-SHUR)
}

recurso (lógicamente hay que interpretar que el precepto se está refiriendo a la imposibilidad de interponer recurso de Casación por razón de la cuantía u otro motivo), el Órgano jurisdiccional podrá convocar a las partes a una comparecencia con la finalidad de dictar su Sentencia< de viva voz>, exponiendo verbalmente los razonamientos en que sustente su decisión, resolviendo sobre los motivos que fundamenten el recurso y la oposición y pronunciar su fallo, de acuerdo con las normas generales sobre las sentencias (art 68 a 71 de la LJCA). La incomparecencia de todas o algunas de las partes no impedirá el dictado de la sentencia en viva voz, precepto que parece pugnar con los principios de los arts. 229.2 y 233 de la Ley Orgánica del Poder Judicial.

Por novedosa que pueda parecer esta innovación consideramos que es cuestionable y precipitada si se tiene en cuenta que el Órgano jurisdiccional, según el art 11.1. Letra H) para conocer de este proceso, no es un Órgano jurisdiccional unipersonal - en cuyo caso sería más justificado esta novedad en analogía con el procedimiento abreviado del art 78.11 LJCA-, sino colegiado.: la Sala de lo Contenciosoadministrativo de la Audiencia Nacional. Efectivamente, el órgano colegiado está sometido a deliberación e incluso formulación de votos particulares lo cual dificulta, a nuestro entender, el encaje de esta modalidad de sentencias, máxime cuando el asunto debatido puede tener especial complejidad cuando afecte a conflictos competenciales entre distintas autoridades De todos modos hay que advertir que el nuevo art 127. Ter no impone esta modalidad de sentencia en todo caso, sino que se configura como potestativa del Órgano jurisdiccional concreto. En cualquier caso, el Secretario Judicial expedirá certificación que recoja todos los pronunciamientos del fallo con expresa indicación de su firmeza e incorporación al Libro de Sentencias y el soporte videográfico de la comparecencia quedara unido al procedimiento

Mayor trascendencia practica presenta la reforma del art 110.1 de la LJCA que como es notorio en su versión primitiva regulaba como novedad la extensión de los efectos de las sentencias firmes a terceros en materia Tributaria y de personar Ahora con la reforma se amplía a la materia de la unidad de mercado, debiendo interpretarse, a nuestro criterio, que la Sentencia en materia Unidad de mercado puede haberse dictado ,tanto en un procedimiento contencioso-administrativo interpuestos por iniciativa propia de un operador económico independiente, como por los interpuestos por la CNMYC, lo cual está llamado a tener mayor irradiación y trascendencia práctica., a pesar de la rigurosidad impuestas por los órganos jurisdiccionales en la aplicación de este precepto. Para la extensión de estos efectos a terceros sigue exigiéndose que < se hubiera reconocido una situación jurídica individualizada a favor de una o varias personas>, .pues si se trata de la anulación de una Disposición

WPS RI-SHUR, nำ2, 2015, vol.1, ISSN: 2387-1768 
de carácter general esta tiene efectos generales desde el día que sea publicado su fallo en el mismo periódico oficial en que lo hubiere sido la disposición anulada. Aun cuando la reforma no hace referencia al art 111 de la LJCA-supuesto de extensión de los efectos de sentencia firme resuelta preferentemente respecto a otros deducidos respecto a un mismo acto o disposición, cuya tramitación se suspendió por no haber sido objeto de acumulación- hay que interpretar por coherencia sistemática que serán análogamente aplicable en materia de unidad de mercado. 